\title{
AVALIAÇÃO AMBIENTAL DO PROCESSO DE INOVAÇÃO TECNOLÓGICA NA COLHEITA FLORESTAL ${ }^{1}$
}

Luis Carlos de Freitas², Carlos Cardoso Machado ${ }^{3}$, Elias Silva ${ }^{3}$, Márcio Lopes da Silva ${ }^{3}$, Ângelo Márcio Pinto Leite ${ }^{4}$ e Haroldo Carlos Fernandes ${ }^{5}$

\begin{abstract}
RESUMO - O objetivo deste trabalho foi avaliar o perfil impactante do processo de inovação tecnológica na colheita florestal. Analisou-se o processo de inovação quando da mudança do subsistema tradicional (Motosserra + Forwarder) para o inovado (Feller Buncher + Clambunk Skidder). Utilizou-se um método consolidado para avaliação de impacto ambiental da inovação tecnológica na agropecuária, que avalia o desempenho ambiental de uma dada metodologia ou tecnologia em relação àquela previamente estabelecida. O método foi adaptado para avaliação de impactos na colheita florestal. Os impactos foram analisados para os indicadores dos meios físico (atmosfera; solo, água); biótico (flora e fauna) e antrópico (emprego; saúde, paisagismo e gestão). Elaboraram-se matrizes para cada indicador, sendo estas ponderadas em relação à escala de ocorrência e fator de importância. Técnicos da área de colheita florestal realizaram o preenchimento das matrizes utilizando coeficientes de alteração previamente definidos. O coeficiente de impacto resultou do produto do coeficiente de alteração pelos fatores de ponderação, sendo avaliado numa escala de $-15 a+15$. O índice geral de impacto foi determinado para o mesmo padrão de escala. De acordo com a média das três avaliações, dois indicadores apresentaram coeficiente de impacto positivo (saúde e gestão); seis mostraram coeficiente negativo (atmosfera, solo, flora, fauna, emprego e paisagismo) e um manteve-se inalterado (água). O índice geral de impacto mostrou-se positivo $(1,29)$, indicando, no contexto global, condições ambienteis favoráveis quando da adoção do subsistema inovado.
\end{abstract}

Palavras-chave: Colheita florestal, Inovação tecnológica e Impacto ambiental.

\section{ENVIRONMENTAL ASSESSMENT OF THE TECHNOLOGICAL INNOVATION PROCESS ON FORESTRY HARVESTING}

\begin{abstract}
This study aimed to evaluate the impacting profile of the technological innovation process on forestry harvesting. We analyzed the innovation process on the traditional subsystem change (chainsaw + forwarder) to the innovative (Feller Buncher + Clambunk Skidder). We used the consolidated method for environmental impact assessment of technological innovation on agro-livestock, which assesses the environmental performance of a certain methodology or technology in relation to that previously established. The method was adapted for the impacts evaluation on forestry harvesting. The impacts were analyzed for the physical media indicators (air, soil, water), biotic (flora and fauna), and anthropic indicators. Matrices were prepared for each indicator, which were weighted in relation to the occurrence scale and importance scale factor. Technicians on the forest harvesting field filled the matrices using changing coefficients previously defined. The impact coefficient resulted from the coefficient changing product by weighting factors, being evaluated on a scale of -15 to +15 . The overall impact index has been determined for the same scale pattern. According to three evaluations average, two indicators showed a positive impact coefficient (health and management), six were negative coefficient (air, soil, flora, fauna, landscape, and employment), and one remained unchanged (water). The overall impact index was positive (1.29), indicating in the global context environmental conditions favorable to the innovative subsystem adoption.
\end{abstract}

Keywords: Forestry harvesting, Technological innovation and Environmental impact.

\footnotetext{
${ }^{1}$ Recebido em 25.11.2009 e aceito para publicação em 16.12.2010.

${ }^{2}$ Departamento de Fitotecnia e Zootecnia, UESB, Bahia, BA, Brasil. E-mail: <luiscarlos_ufv@yahoo.com.br>.

${ }^{3}$ Departamento de Engenharia Florestal,UFV, Brasil. E-mail: <machado@ufv.br>, <eshamir@ufv.br>e <marlosil@ufv.br>.

${ }^{4}$ Departamento de Engenharia Florestal, UFVJM, MG, Brasil. E-mail: <ampleite@yahoo.com.br>.

${ }^{5}$ Departamento de Engenharia Agrícola, UFV, MG, Brasil. E-mail: <haroldo@ufv.br>.
} 


\section{INTRODUÇÃO}

Analisando o histórico da colheita florestal no Brasil, percebeu-se que a atividade passou por significativas mudanças tecnológicas nas últimas décadas; as operações evoluíram de um processo manual para o semimecanizado, adquirindo nível mais expressivo de mecanização. Até a década de 1940 praticamente não havia emprego de maquinários nas operações de colheita florestal (MACHADO et al., 2008). As operações de corte eram realizadas de forma rudimentar com o uso de machado, foices e serras. A extração também se baseava em métodos rudimentares, principalmente através dos trabalhos braçal e animal (FREITAS et al., 2009). No período de 1960 a 1970 ocorreram avanços no setor, com o aparecimento das primeiras motosserras. A modernização das operações da colheita florestal teve início a partir de 1970, quando a indústria nacional começou a produzir maquinário de portes leve e médio. Nesse período surgiram as motosserras profissionais, os tratores agrícolas equipados com pinça hidráulica traseira ou Miniskidder e os autocarregáveis (PARISE, 2005). A partir da década de 1980 surgiram grandes alterações tecnológicas na colheita florestal, com a substituição das motosserras pelo Feller Buncher e Harvester (MALINOVSKI et al., 2008). Nessa década surgiram também os Skidders, os quais passaram a substituir os tratores agrícolas adaptados para o processo de extração florestal. A partir da década de 1990 houve grande modernização do processo de mecanização da colheita florestal dada, sobretudo, pela abertura das importações (MACHADO et al., 2008).

A revolução tecnológica na colheita florestal trouxe, contudo, novo cenário com relação aos seus danos ambientais. As empresas passaram a utilizar maquinários pesados nas operações, agravando, assim, os processos de compactação (SEIXAS; JUNIOR, 2001) e erosão do solo (ANDRADE et al., 2000; FREITAS et al., 2007). Os danos à vegetação de sub-bosque e às cepas também foram agravados em algumas circunstâncias, principalmente pelo processo de arraste com os modernos Skidders (LIRA FILHO, 1993). No contexto social, muitas mudanças aconteceram, como: redução da mão de obra e dos índices de acidentes, melhoria da qualificação profissional, aumento da remuneração e redução do custo de produção (FREITAS, 2008). A diminuição do custo de produção é de fundamental importância na colheita florestal, já que essa atividade, juntamente com o transporte, responde por cerca de $50 \%$, ou mais, dos custos totais da madeira posta na indústria (BAGIO; e STOHR, 1978; REZENDE et al., 1983).

A modernização da colheita florestal trouxe grandes alterações nos aspectos físicos, bióticos e antrópicos, traçando, assim, um perfil ambiental desconhecido e que deve, portanto, ser analisado de forma criteriosa, visando inserir a colheita florestal no novo contexto da sustentabilidade. Este trabalho teve como objetivo avaliar os impactos ambientais decorrentes do processo de inovação tecnológica na colheita florestal. Os objetivos específicos foram: determinar, por meio de matriz de ponderação, os coeficientes de impacto ambiental para os indicadores dos aspectos físico, biótico e antrópico, à época da mudança do subsistema Motosserra + Forwarder (pré-inovação) para Feller Buncher + Clambunk Skidder (pós- inovação); determinar o índice geral de impacto ambiental para o processo de inovação avaliado; e discutir sobre os principais fatores responsáveis pelas alterações ambientais (positivas e negativas), por ocasião da adoção do processo de inovação tecnológica em estudo.

\section{MATERIAL E MÉTODOS}

\subsection{Avaliação de impactos ambientais da inovação tecnológica na colheita florestal}

Existe à disposição dos avaliadores de impacto ambiental vasto arsenal metodológico, com mais de 100 métodos descritos para os mais variados propósitos e situações (BISSET, 1987; CANTER, 1996; OREA, 1998). No caso em estudo, trabalhou-se com um método consolidado para avaliação de impacto ambiental da inovação tecnológica na agropecuária (AMBITECAGRO), desenvolvido pela Embrapa Meio Ambiente, que avalia o desempenho ambiental de dada tecnologia ou metodologia em relação àquela previamente estabelecida (RODRIGUES et al., 2003). O sistema AMBITEC foi direcionado para avaliação dos impactos ambientais oriundos dos avanços tecnológicos na colheita florestal. A referida metodologia envolveu as seguintes etapas.

\subsubsection{Definição e descrição dos subsistemas de colheita florestal avaliados}

Foram avaliados os impactos ambientais no subsistema inovado (Feller Buncher + Clambunk Skidder), tomando como referência o modal de colheita tradicional 
(Motosserra + Forwarder). Uma empresa produtora de celulose, localizada no Estado de Minas Gerais, foi utilizada como parâmetro para obtenção dos dados.

No subsistema inovado, a derrubada foi realizada por meio do Feller Buncher, sendo o desgalhamento e destopamento executados de forma manual. A extração foi realizada com o auxílio do Clambunk Skidder, o qual foi responsável pelo arraste dos feixes de toras até as margens das estradas. No subsistema tradicional, as operações de corte (derrubada, desgalhamento, destopamento e traçamento) foram realizadas de forma semimecanizada. As árvores abatidas foram traçadas num comprimento de 2,20 m. Os toretes foram extraídos do talhão com o auxílio do Forwarder, máquina responsável pelo carregamento da madeira dentro do talhão e descarregamento nas margens das estradas ou no pátio intermediário.

\subsubsection{Definição dos indicadores e componentes e elaboração das matrizes}

Para avaliação dos impactos ambientais decorrentes do processo de inovação tecnológica na colheita florestal foram definidos indicadores pertencentes aos aspectos físico, biótico e antrópico. Os indicadores foram analisados com base nos respectivos componentes. Os indicadores e componentes avaliados no aspecto físico foram: atmosfera (gases de efeito-estufa, material particulado, ruído e odores), solo (erosão, compactação, exportação de nutrientes e perda de matéria orgânica) e água (turbidez, assoreamento e redução da vazão). No aspecto biótico, analisaram-se os indicadores flora e fauna. A flora foi representada pelos seguintes componentes: danos à vegetação de sub-bosque; danos à vegetação plantada, danos à vegetação de reserva legal e danos à vegetação de preservação permanente. A fauna foi avaliada em relação a três componentes: danos à fauna terrestre (vertebrados), danos à fauna terrestre (invertebrados) e danos à fauna aquática. No aspecto antrópico, os indicadores e componentes avaliados foram: emprego (qualificação, oferta de emprego, redução da terceirização e salário), saúde (riscos de acidentes, perda das condições ergonômicas e geração de resíduos), paisagismo (depreciação da paisagem pela derrubada da floresta, depreciação visual pela disposição da madeira e dos restos vegetais no talhão e exposição do solo no processo de extração) e gestão (produtividade, redução do custo de produção, qualidade de vida e treinamento).
Após definição dos indicadores e componentes, procedeu-se à elaboração das matrizes de ponderação, sendo três referentes ao aspecto físico, duas ao aspecto biótico e quatro ao aspecto antrópico. Cada indicador, com os respectivos componentes, resultou numa matriz de ponderação, de forma a proceder-se à avaliação de impacto ambiental da inovação tecnológica na colheita florestal.

\subsection{Coleta de dados}

O primeiro passo para obtenção dos dados foi a ponderação dos componentes das matrizes em relação à escala de ocorrência e fator de importância (Tabela 1). No caso da escala de ocorrência, o fator de ponderação foi selecionado de forma a exprimir o aumento do impacto conforme a escala espacial, agravando-o quando a escala de ocorrência se estende além dos limites da unidade produtiva (RODRIGUES et al., 2003). Foram considerados, portanto, os seguintes fatores de ponderação: impacto pontual (impacto que se restringe à área de corte, com fator de ponderação igual a 1); impacto local (impacto de maior abrangência em relação ao impacto pontual, restringindo-se a área do projeto, com fator de ponderação igual a 2) e impacto no entorno (impacto de maior abrangência em relação ao impacto local, extravasando a área do projeto, com fator de ponderação igual a 5).

O fator de importância consistiu numa etapa para normalização devido aos diferentes números de componentes de cada indicador e também para consideração do peso relativo de impacto nos respectivos componentes avaliados. O somatório do fator de importância, de todos os componentes, de determinado indicador, resultou em +1 ou -1 (um). Neste trabalho, o fator de importância adotado foi aquele obtido da média das três avaliações, em que cada avaliador expressou sua ponderação de acordo com o grau de importância dos respectivos componentes.

Após ponderação, procedeu-se ao preenchimento das matrizes utilizando os coeficientes de alteração padronizados. Foram adotados os seguintes coeficientes: $(+3)$ para grande aumento do componente, $(+1)$ para moderado aumento do componente, $(0)$ para componente que não sofreu alteração, (-3) para grande diminuição do componente e (-1) para moderada diminuição do componente.

Revista Árvore, Viçosa-MG, v.35, n.2, p.329-339, 2011 
As matrizes foram preenchidas de forma individual, tomando como referência técnicos da área de colheita florestal que vivenciaram o progresso tecnológico em estudo. A avaliação foi realizada com base na análise de três representantes de uma empresa florestal. Cada um preencheu um total de nove matrizes referentes aos indicadores em estudo.

\subsection{Determinação do coeficiente e do índice geral de impacto}

Os coeficientes de impacto resultaram do produto do coeficiente de alteração (padronizado) pelos fatores de ponderação (escala de ocorrência e fator de importância) (Tabela 1). Foram calculados os coeficientes de impacto de todos os componentes de cada um dos nove indicadores avaliados. O somatório dos coeficientes de todos os componentes, de determinado indicador, resultou no coeficiente de impacto total do respectivo indicador. Este se enquadrou numa escala de -15 a +15 , captando, assim, as alterações positivas e negativas proporcionadas pela diversificação tecnológica no subsistema avaliado.

Para uma análise global, os nove indicadores contemplados no estudo foram também ponderados (somatório igual a 1), sendo os valores resultantes dessa ponderação multiplicados pelos respectivos coeficientes de impactos dos indicadores, como forma de se determinar o índice geral de impacto no processo de inovação tecnológica analisado.

\section{RESULTADOS}

Os fatores de importância mais expressivos foram observados nos componentes "ruído" $(-0,55)$ - indicador atmosfera e “assoreamento” (-0,53) - indicador água. Sete dos nove indicadores avaliados apresentaram, em pelo menos uma das repetições, valor máximo para o coeficiente de alteração (+ 3 ou - 3) (Tabela 2).

Dos nove indicadores avaliados, três apresentaram variação de sinal para o coeficiente total de impacto dentro das repetições, sendo dois pertencentes ao aspecto físico (solo e água) e um ao aspecto antrópico (emprego). Para os demais indicadores foram observados, no entanto, maior homogeneidade dentro das repetições (Figura 1).

De acordo com a média das três repetições, dois indicadores apresentaram coeficiente total de impacto positivo (saúde e gestão), e seis mostraram coeficiente total de impacto negativo (atmosfera, solo, flora, fauna, emprego e paisagismo), sendo observado, ainda, um quadro inalterado para o indicador água (Figura 1). O índice geral médio de impacto ambiental para o processo de inovação tecnológica em estudo apresentou valor de 1,29 , considerando-se uma escala com amplitude de -15 a +15 (Tabela 3).

Tabela 1 - Matriz de ponderação (algébrica) utilizada para determinação do coeficiente de impacto ambiental da inovação tecnológica na colheita florestal (adaptado do sistema AMBITEC - AGRO, RODRIGUES et al., 2003).

Table 1 - Weighing matrices (algebraic) used for the coefficient determination of the environmental impact by the technological innovation on forestry harvesting.

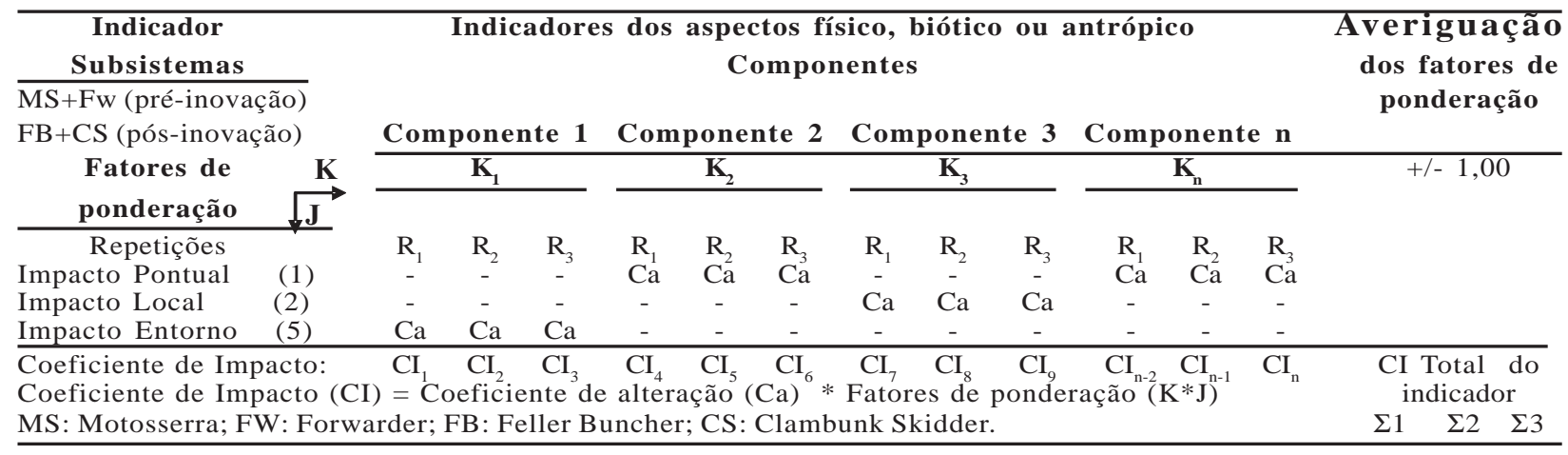

Fonte: adaptado do sistema AMBITEC - AGRO, RODRIGUES et al., 2003.

Source: adapted from the AMBITEC-AGRO system (RDRIGUES et al., 2003).

Revista Árvore, Viçosa-MG, v.35, n.2, p.329-339, 2011 
Tabela 2 - Parâmetros quantitativos utilizados na determinação dos coeficientes de impacto ambiental da inovação tecnológica na colheita florestal.

Table 2 - Quantitative parameters used in the determination of the environmental impact coefficients of the technological innovation on forestry harvesting.

\begin{tabular}{|c|c|c|c|c|}
\hline \multirow{2}{*}{$\begin{array}{c}\begin{array}{c}\text { Indicadores/ponderação/ } \\
\text { coeficiente alteração }\end{array} \\
\text { Atmosfera } \\
\end{array}$} & \multicolumn{4}{|c|}{$\begin{array}{l}\text { Componentes dos indicadores/ Resultados da } \\
\text { ponderação e do coeficiente de alteração }\end{array}$} \\
\hline & Gases de efeito estufa & Material particulado & Ruídos & Odores \\
\hline $\begin{array}{l}\text { Ponderação média } \\
\text { fator de importância }\end{array}$ & $-0,18$ & $-0,17$ & $-0,55$ & $-0,10$ \\
\hline Ponderação Escala de ocorrência & Impacto no entorno (5) & Impacto pontual (1) & Impacto Local (2) & Impacto pontual (1) \\
\hline Coeficiente de alteração & R1 (1) R2 (0) R3 (-1) & R1 (3) R2 (0) R3 (1) & R1 (3) R2 (1) R3 (1) & R1 (1) R2 (0) R3 (-1) \\
\hline Solo & Erosão & Compactação & Exportação nutrientes & Perda matéria orgânica \\
\hline $\begin{array}{l}\text { Ponderação média Fator de } \\
\text { importância }\end{array}$ & $-0,43$ & $-0,27$ & $-0,14$ & $-0,16$ \\
\hline Ponderação Escala de ocorrência & Impacto pontual (1) & Impacto pontual (1) & Impacto pontual (1) & Impacto pontual (1) \\
\hline Coeficiente de alteração & R1 (1) R2 (1) R3 (-1) & R1 (1) R2 (1) R3 (-1) & R1 (3) R2 (0) R3 (1) & R1 (0) R2 (0) R3 (-1) \\
\hline Água & Turbidez & Assoreamento & Redução da vazão & \\
\hline $\begin{array}{l}\text { Ponderação média Fator de } \\
\text { importância }\end{array}$ & $-0,24$ & $-0,53$ & $-0,23$ & - \\
\hline Ponderação Escala de ocorrência & Impacto Local (2) & Impacto no entorno (5) & Impacto Local (2) & - \\
\hline Coeficiente de alteração & R1 (1) R2 (0) R3 (-1) & R1 (1) R2 (0) R3 (-1) & R1 (0) R2 (0) R3 (0) & - \\
\hline Flora & Danos sub-bosque & Danos vegetação plantada & Danos a floresta (APP) & Danos a floresta (RL) \\
\hline $\begin{array}{l}\text { Ponderação média Fator } \\
\text { de importância }\end{array}$ & $-0,15$ & $-0,19$ & $-0,36$ & $-0,30$ \\
\hline Ponderação Escala de oco & Impacto pontual (1) & Impacto pontual (1) & Impacto local (2) & Impacto local (2) \\
\hline Coeficiente de alteração & R1 (3) R2 (0) R3 (3) & R1 (3) R2 (0) R3 (3) & R1 (1) R2 (0) R3 (1) & $\mathrm{R} 1(-1) \mathrm{R} 2(0) \mathrm{R} 3(-1$ \\
\hline Fauna & Danos aos vertebrados & Danos aos invertebrados & Danos fauna aquática & E \\
\hline $\begin{array}{l}\text { Ponderação média Fator } \\
\text { de importância }\end{array}$ & $-0,32$ & $-0,40$ & $-0,28$ & - \\
\hline Ponderação Escala de ocorrência & Impacto pontual (1) & Impacto pontual (1) & Impacto Local (2) & - \\
\hline Coeficiente de alteração & $\mathrm{R} 1(0)$ R2 (0) R3 (1) & R1 (1) R2 (0) R3 (1) & R1 (0) R2 (0) R3 (1) & - \\
\hline Emprego & Qualificação & Oferta de emprego & Redução terceirização & Salário \\
\hline $\begin{array}{l}\text { Ponderação média Fator } \\
\text { de importância }\end{array}$ & 0,30 & 0,20 & 0,23 & 0,27 \\
\hline Ponderação Escala de ocorrência & Impacto pontual (1) & Impacto entorno (5) & Impacto entorno (5) & Impacto pontual (1) \\
\hline Coeficiente de alteração & R1 (1) R2 (1) R3 (3) & R1 (-3) R2 (-1) R3 (-1) & R1 (-1) R2 (-1) R3 (1) & R1 (3) R2 (1) R3 (3) \\
\hline Saúde & Riscos de acidentes & Perdas ergonômicas & Geração de resíduos & ----------- \\
\hline $\begin{array}{l}\text { Ponderação média Fator de } \\
\text { importância }\end{array}$ & $-0,44$ & $-0,39$ & $-0,17$ & - \\
\hline Ponderação Escala de ocorrência & Impacto pontual (1) & Impacto pontual (1) & Impacto Local (2) & - \\
\hline Coeficiente de alteração & R1 (-3) R2 (-3) R3 (-3) & R1 (-3) R2 (-3) R3 (-3) & R1 (-1) R2 (-3) R3 (-3) & - \\
\hline \multirow[t]{2}{*}{ Paisagismo } & Depreciação pela remoção & Depr. pela disposição da & Exposição do solo no & ------------ \\
\hline & da floresta & madeira e galhada talhão & processo de extração & \\
\hline $\begin{array}{l}\text { Ponderação média Fator de } \\
\text { importância }\end{array}$ & $-0,28$ & $-0,30$ & $-0,42$ & - \\
\hline Ponderação Escala de ocorrência & Impacto entorno (5) & Impacto Local (2) & Impacto Local (2) & - \\
\hline Coeficiente de alteração & R1 (1) R2 (0) R3 (1) & R1 (1) R2 (0) R3 (3) & R1 (0) R2 (0) R3 (3) & - \\
\hline Gestão & Produtividade & Red. Custo de produção & Qualidade de vida & Treinamento \\
\hline Ponderação média Fator de importân & 0,25 & 0,35 & 0,20 & 0,20 \\
\hline Ponderação Escala de ocorrência & Impacto pontual (1) & Impacto pontual (1) & Impacto pontual (1) & Impacto pontual (1) \\
\hline Coeficiente de alteração & R1 (3) R2 (3) R3 (3) & R1 (3) R2 (1) R3 (3) & R1 (1) R2 (3) R3 (3) & R1 (3) R2 (3) R3 (3) \\
\hline
\end{tabular}


Tabela 3 - Ponderação dos indicadores e expressão do índice geral de impacto ambiental (médio) da inovação tecnológica na colheita florestal.

Table 3 - Indicators weighing and the general index expression of the environmental impact (medium) from the technological innovation on forestry harvesting.

\begin{tabular}{cccc}
\hline $\begin{array}{c}\text { Indicador de Impacto } \\
\text { ambiental }\end{array}$ & $\begin{array}{c}\text { Peso do indicador } \\
(\mathrm{a})\end{array}$ & $\begin{array}{c}\text { Coeficiente de impacto } \\
\text { médio }(\mathrm{b})\end{array}$ & $\begin{array}{c}\text { Índice de impacto } \\
(\mathrm{axb})\end{array}$ \\
\hline Atmosfera & $\mathbf{0 , 0 5}$ & $\mathbf{- 2 , 0 6}$ & $-\mathbf{0 6}, \mathbf{1 0}$ \\
Solo & 0,13 & $-1,83$ & $-0,24$ \\
Agua & 0,14 & 0,00 & $-0,00$ \\
Flora & 0,12 & $-0,76$ & $-0,09$ \\
Fauna & 0,12 & $-0,92$ & $-0,07$ \\
Emprego & 0,13 & 3,28 & -12 \\
Saúde & 0,14 & $-2,57$ & 0,46 \\
Paisagismo & 0,05 & 13,17 & $-0,13$ \\
Gestão & 0,12 & 1,58
\end{tabular}

(a) - valores obtidos em função do grau de importância dos indicadores.

* Valor compreendido numa escala de -15 a +15.

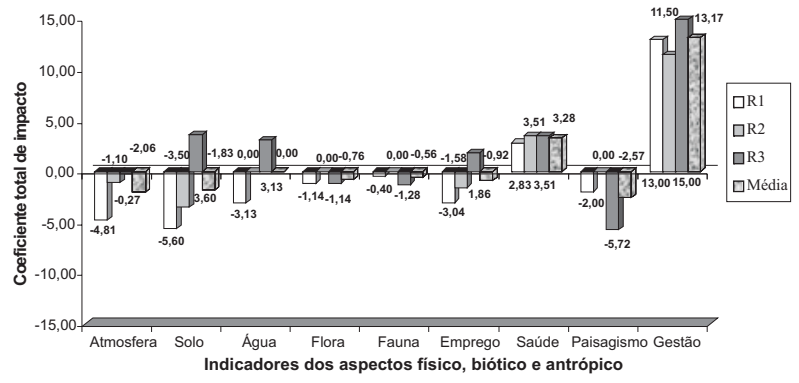

Figura 1-Coeficiente total de impacto ambiental da inovação tecnológica na colheita florestal para os indicadores físico, biótico e antrópico, obtidos nas três repetições.

Figure 1 - Total Coefficient of environmental impact of the technological innovation on forestry harvesting for the physical, biotic, and antropic indicators, obtained by three repetitions.

\section{DISCUSSÃO}

\subsection{Análise dos impactos ambientais no processo de inovação tecnológica avaliado}

O processo de inovação tecnológica em estudo promoveu mudança no sistema de toras curtas para o sistema de toras compridas, culminando numa série de alterações ambientais nos aspectos físico, biótico e antrópico, as quais se encontram descritas nos tópicos subsequentes.

\subsubsection{Atmosfera}

Este indicador foi representado pelos componentes gases de efeito-estufa, material particulado, ruído e odores. Os gases de efeito-estufa apresentaram alterações positiva e negativa em nível moderado (Tabela 2). A diminuição desses gases em uma das avaliações esteve relacionada com a operação de corte, uma vez que o Feller Buncher apresenta motores mais modernos em comparação com as motosserras (Tabela 2). Silva (1995) relatou a depreciação da qualidade do ar proporcionada pela emissão de gases resultantes da combustão pelo uso de motosserras. As máquinas mais modernas são capazes de controlar automaticamente o consumo de combustível através de um processo eletrônico, o que acaba proporcionando dois ganhos: economia de combustível e, consequentemente, diminuição da poluição (JUNIOR et al., 2007). Em uma das repetições, no entanto, percebeu-se uma opinião inversa. Isso ocorreu em razão de a operação de corte mecanizado demandar serviços relacionados à distribuição de peças e abastecimento de máquinas no campo, o que potencializou o trânsito de veículos nas áreas florestais, agravando, assim, a emissão de poluentes no subsistema inovado (Tabela 2). O material particulado teve aumento em duas avaliações na adoção da inovação tecnológica (Tabela 2). Isso foi explicado pela mudança no processo de extração, visto que o arraste com o Clambunk Skidder condiciona maior suspensão de particulados quando comparado com o baldeio com o Forwarder. Nesse caso, teve-se ainda um agravante, dada a substituição da motosserra pelo Feller Buncher. Segundo Andrade (1998), o corte mecanizado proporciona a emissão de particulados para a atmosfera, agravando os impactos no meio físico. Os níveis de ruído apresentaram alterações positivas em todas as avaliações durante a mudança do subsistema 
tradicional para o inovado (Tabela 2). A mudança do baldeio para o arraste condicionou aumento do barulho em virtude do contado da madeira com o solo.

O coeficiente total de impacto mostrou-se negativo em todas as repetições, indicando que o processo de inovação em questão não proporcionou melhorias ambientais em relação ao referido indicador (Figura 1).

\subsubsection{Solo}

O indicador solo foi composto por quatro componentes: compactação, erosão, exportação de nutrientes e perda de matéria orgânica. A compactação e erosão mostraram moderado aumento na maioria das repetições por ocasião da adoção do subsistema inovado (Tabela 2). A substituição das motosserras pelos Feller Bunchers foi fator decisivo para o aumento de tais componentes. Com o progresso tecnológico, as empresas passaram a utilizar maquinários pesados nas operações, agravando, assim, os processos de compactação (SEIXAS; e JUNIOR, 2001) e erosão do solo (ANDRADE et al., 2000). De acordo com Seixas (2001), a compactação pode proporcionar maior ou menor suscetibilidade aos processos erosivos, dependendo das circunstâncias. Segundo Wästerlund (1994), a compactação do solo geralmente ocorre em consequência de cargas ou pressões aplicadas durante o tráfego de máquinas e o andar de animais ou pessoas.

Analisando a exportação de nutrientes, notou-se que todas as repetições mostraram aumento no grau de alteração à época da substituição do subsistema tradicional pelo inovado (Tabela 2). No subsistema Motosserra + Forwarder (toras curtas), a madeira é processada dentro dos talhões, favorecendo a manutenção dos nutrientes no sítio (MACHADO, 1989). No subsistema Feller Buncher + Clambunk Skidder, o processamento ocorre nas margens das estradas, fato que potencializa a exportação de nutrientes.

O coeficiente de impacto ambiental apresentou maior valor para o componente erosão, o que pode ser explicado pela ponderação expressiva do respectivo componente em relação ao fator de importância $(-0,43)$ (Tabela 2). Os componentes desse indicador, por estarem restritos ao âmbito pontual, foram normalizados em relação à escala de ocorrência mais abrangente (impacto no entorno).
O coeficiente total de impacto mostrou-se negativo na maioria das repetições, evidenciando, no contexto geral, condições ambientais desfavoráveis para o respectivo indicador na adoção do subsistema inovado (Figura 1).

\subsection{3. Água}

Este indicador foi avaliado com base nos seguintes componentes: turbidez, assoreamento e redução da vazão. A adoção do subsistema inovado (Feller Buncher + Clambunk Skidder) promoveu alterações positiva e negativa, em nível moderado, em relação aos componentes turbidez e assoreamento (Tabela 2). No entanto, foi considerado o fato agravante do arraste com Clambunk Skidder, em termos de sulcamento do solo (SILVA, 2008), o que potencializou os referidos componentes. Em contrapartida, a utilização do Forwarder antes da inovação acarretou também impactos em relação aos componentes turbidez e assoreamento. O Forwarder trafega repetitivamente no mesmo traçado, aspecto que potencializa danos diretos ao solo (FREITAS et al., 2007; FREITAS, 2008), trazendo, consequentemente, impactos indiretos em relação aos corpos hídricos (SILVA, 1994). Cabe ressaltar que o deslocamento dessa máquina na forma que é conduzido acaba configurando como estratégia eficaz na extração de madeira dos talhões, proporcionando, portanto, melhores rendimentos operacionais.

Entre os componentes avaliados, o assoreamento foi o que apresentou maior coeficiente de impacto, o que pode ser explicado em razão de sua expressiva ponderação em relação à escala de ocorrência e fator de importância (Tabela 2).

\subsubsection{Flora}

Este indicador foi analisado de acordo com os seguintes componentes: danos à vegetação de subbosque, danos à vegetação plantada, danos à floresta de preservação permanente e danos à floresta de reserva legal.

O subsistema inovado (Feller Buncher + Clambunk Skidder) proporcionou alteração significativa em relação aos danos à vegetação presente dentro dos talhões (sub-bosque e floresta plantada) (Tabela 2). O arraste com Clambunk Skidder foi considerado elemento complicador quando comparado com o processo de extração com o Forwarder. Neste último, os danos ocorrem basicamente pelo contato dos rodados com a vegetação,

Revista Árvore, Viçosa-MG, v.35, n.2, p.329-339, 2011 
já com Clambunk Skidder, além do dano citado, tem-se também o impacto provocado pelo contato da madeira com o solo (LIRA FILHO, 1993). Com relação à reserva legal, o subsistema inovado mostrou-se menos impactante (Tabela 2). Isso ocorreu em virtude do melhor direcionamento de queda das árvores na derrubada mecanizada com o Feller Buncher (FREITAS, 2004). Os danos relacionados à floresta de preservação permanente foram, no entanto, moderadamente superiores no subsistema inovado. Esse subsistema, por contemplar a colheita mais mecanizada, acaba proporcionando danos mais expressivos ao solo (compactação), impactando, de forma indireta, a microbacia, com possíveis danos à floresta de preservação permanente (FREITAS, 2008).

\subsubsection{Fauna}

O indicador fauna foi representado pelos componentes danos à fauna terrestre (incluindo vertebrados e invertebrados) e danos à fauna aquática. Esse indicador não apresentou grandes alterações quando da adoção do processo de inovação (Tabela 2). O subsistema inovado, mesmo que de forma pouco acentuada, mostrou adicional de dano em relação aos componentes avaliados. A operação de arraste com Clambunk Skidder foi mais problemática quando comparada com a extração com o Forwarder. O contato das peças de madeira com o solo na operação de arraste proporcionou danos à fauna terrestre, bem como à fauna aquática. No primeiro caso, os impactos são decorrentes da destruição da vegetação de sub-bosque, o que reflete em danos indiretos à fauna terrestre (FREITAS, 2008). A desestruturação da camada superficial do solo pelo arraste gera também impactos indiretos aos corpos hídricos, promovendo danos aos componentes bióticos desses ecossistemas (SILVA, 1994).

O coeficiente total de impacto apresentou-se negativo em duas das três repetições, refletindo aumento da problemática ambiental para o respectivo indicador, durante a adoção do subsistema inovado (Figura 1).

\subsubsection{Emprego}

Este indicador foi representado pelos componentes qualificação, emprego, terceirização e salário. Os dados provenientes das três repetições mostraram que a inovação tecnológica em questão contribuiu, de forma positiva, para a melhoria da qualificação profissional dentro da empresa florestal (Tabela 2). Com relação à oferta de empregos, percebeu-se aspecto inverso, com uma das avaliações mostrando, inclusive, forte retração (Tabela 2). A substituição das motosserras pelo Feller Bunchers proporcionou ganhos de produção significativos na atividade de corte (derrubada) e, consequentemente, diminuição no número de empregos na atividade (DURATEX, 1999).

O processo de terceirização foi também avaliado nesse contexto e caracterizado como impacto negativo, principalmente pelo fato de os trabalhadores integrantes desse sistema não usufruírem os mesmos benefícios dos funcionários das empresas florestais. Foi constatada nesse processo de inovação tendência de redução da terceirização (Tabela 2). Analisando a questão salarial, percebeu-se um consenso, em que todas as repetições apontaram para alteração positiva do respectivo componente (Tabela 2). O subsistema inovado proporcionou melhoria da qualificação, em que os operadores passaram naturalmente a receber melhores salários. Tais resultados estão de acordo com a pesquisa realizada por Freitas (2004), que avaliou os impactos ambientais decorrentes das atividades de colheita florestal em plantios equiâneos de eucalipto.

O coeficiente total de impacto mostrou-se negativo na maioria das repetições (Figura 1), indicando, no contexto global, aspectos sociais desfavoráveis para o indicador em questão, por ocasião da adoção do subsistema inovado.

\subsubsection{Saúde}

Este indicador foi analisado por meio dos componentes riscos de acidentes, perda das condições ergonômicas e geração de resíduos. O processo de inovação tecnológica proporcionou redução significativa dos respectivos componentes (Tabela 2). Os riscos de acidentes foram minimizados em virtude da substituição do corte semimecanizado pelo corte mecanizado (Tabela 2). De acordo com Souza et al. (2008), a operação de corte semimecanizado é considerada um dos trabalhos mais pesados e de mais alto risco de acidentes. Em razão disso, houve também ganhos, em termos ergonômicos, quando da adoção do processo inovado. A criação de novos postos de trabalho dentro de cabines, bem como a diminuição do esforço físico nas atividades, potencializou o respectivo componente, promovendo redução significativa das perdas ergonômicas (Tabela 2). 
A inovação tecnológica proporcionou ainda outro aspecto positivo relacionado à redução da quantidade de lixo gerado nos projetos florestais. A atividade semimecanizada contempla maior contingente de trabalhadores nas áreas de corte, contribuindo, assim, com maior produção de lixo nesses ambientes.

A inovação tecnológica mostrou-se favorável em relação ao indicador em questão, em que o coeficiente total de impacto atingiu valores positivos nas três repetições (Figura 1 ).

\subsubsection{Paisagismo}

O indicador paisagismo foi composto pelos componentes depreciação da paisagem pela remoção da floresta, depreciação visual pela disposição da madeira e dos restos vegetais no talhão e exposição do solo no processo de extração. A depreciação da paisagem foi avaliada em relação à distribuição espacial das áreas colhidas. Nos sistemas altamente mecanizados, é economicamente mais difícil contemplar o corte em mosaico e atenuar os impactos visuais da colheita. Isso pode ser explicado pelo alto custo envolvido nas operações mecanizadas. Assim, a nova logística para redistribuição espacial de máquinas nas áreas de corte resultaria em perdas consideráveis de produção. Nesse contexto, o subsistema inovado mostrou-se desfavorável com relação ao referido componente, apresentando moderado aumento em duas avaliações (Tabela 2).

Quando foi avaliada a alteração do aspecto paisagístico pela distribuição da madeira e dos restos vegetais no talhão, percebeu-se aumento dos impactos negativos em virtude do processo de inovação (Tabela 2). A exposição do solo no processo de extração também foi mais significativa no subsistema inovado, dada a mudança do sistema de toras curtas para o sistema de toras compridas (FREITAS, 2008) (Tabela 2).

\subsubsection{Gestão}

Este indicador foi avaliado mediante os parâmetros produtividade, redução do custo de produção, qualidade de vida e treinamento. Foi observada grande alteração da produtividade no subsistema inovado (Tabela 2). Isso ocorreu em virtude do melhor rendimento do Feller Buncher em relação ao sistema semimecanizado. O melhor rendimento no corte mecanizado acaba viabilizado esse tipo de operação (MACHADO; LOPES, 2008), justamente em virtude da redução do custo de produção (Tabela 2).
O subsistema inovado proporcionou, ainda, alteração positiva em relação ao componente qualidade de vida, podendo ser explicado pelos avanços ergonômicos e melhorias de salário nas atividades mecanizadas (Tabela 2). O treinamento apresentou alteração positiva por ocasião da adoção do processo de inovação. As operações mecanizadas requerem maior grau de treinamento, como forma de obter o máximo de produtividade e, ao mesmo tempo, compatibilizar os altos custos operacionais. Esses resultados estão de acordo com aqueles obtidos por Freitas (2008), o qual avaliou os impactos ambientais nas atividades de colheita florestal, nos meios físico, biótico e antrópico.

Todos os componentes do indicador gestão foram normalizados em relação à escala de ocorrência máxima (impacto no entorno) (Tabela 2). Essa normalização se deu em virtude de os respectivos componentes estarem restritos ao âmbito pontual.

A inovação em questão proporcionou coeficiente total de impacto positivo e bastante expressivo nas três repetições (Figura 1).

\subsection{Avaliação geral de impactos ambientais do processo de inovação tecnológica na colheita florestal para os subsistemas em estudo}

O índice geral médio de impacto, embora tenha atingido valor pouco expressivo em relação à escala, mostrou-se positivo $(1,29)$, sendo, contudo, fortemente influenciado pelo indicador gestão, o qual foi, juntamente com o indicador saúde, os únicos a apresentar valores positivos (Tabela 3).

\section{CONCLUSÕES}

Avaliando os resultados deste trabalho, percebeu-se que os coeficientes médios de impacto ambiental, à época da mudança do subsistema tradicional para o inovado, mostraram-se favoráveis para apenas 33,33\% dos indicadores. Embora grande parte desses indicadores tenha mostrado coeficiente médio de impacto ambiental negativo, o índice geral de impacto mostrou-se positivo, o que foi proporcionado pela grande expressividade do indicador gestão.

O processo de inovação proporcionou alterações ambientais nos meios físico, biótico e antrópico, sendo essas relacionadas com a mudança do sistema de toras curtas (pré-inovação) para o de toras compridas (pósinovação). No aspecto físico, entre outras mudanças, percebeu-se agravamento dos processos erosivos do

Revista Árvore, Viçosa-MG, v.35, n.2, p.329-339, 2011 
solo, pela mudança no processo de extração (baldeio para arraste). Analisando o aspecto biótico, percebeu-se atenuação dos danos ambientais em relação à floresta do entorno, a qual foi proporcionada pela melhor eficiência no direcionamento de queda das árvores, por ocasião da extração mecanizada com o Feller Buncher. Em relação ao aspecto antrópico, ocorreu retração na oferta de empregos pela substituição do corte semimecanizado pelo mecanizado, porém houve também alterações positivas, principalmente em relação aos fatores salários e qualificação profissional.

A metodologia utilizada possibilitou variação restrita dos coeficientes de alteração (padronizado), contribuindo nesse aspecto para diminuição do grau de subjetividade dos coeficientes de impacto. É inevitável, contudo, a interferência da subjetividade em trabalhos dessa natureza, assim como forma de respaldar os dados desta pesquisa, e cabe ressaltar que ela se concretizou como estudo de caso. Nesse contexto, torna-se possível um comportamento diferenciado dos referidos coeficientes de impacto quando eles e os subsistemas são avaliados em outras realidades, sejam essas o nível de experiência dos avaliadores, o grau de conhecimento sobre a temática ambiental deles, as condições topográficas locais ou, mesmo, o próprio grau de subjetividade implícito no método de análise.

\section{REFERÊNCIAS}

ANDRADE, S. C. Avaliação técnica, social, econômica e ambiental de dois sistemas de colheita florestal no litoral norte da Bahia1998. 125f. Dissertação (Mestrado em Ciência Florestal) Universidade Federal de Viçosa, Viçosa, MG, 1998.

ANDRADE, S. C. et al. Análise dos efeitos da compactação do solo sobre a regeneração das cepas de eucalipto. Revista Árvore, v.24, n.3, p.261-268, 2000.

BAGIO, A. J.; STOHR, G. W. D. Resultados preliminares de um levantamento dos sistemas de exploração usados em florestas implantadas no Sul do Brasil. Floresta, v.9, n.2, p.76-96, 1978.

BISSET, R. Methods for environmental impact assessment: a selective survey with case studies. In: BISWAS, A. K.; GEPING, Q. (Eds.).

Environmental impact assessment for developing countries. London: Tycoly International, 1987.p.3-64.
CANTER, L.W.Environmental Impact

Assessment. New York: McGraw-Hill, 1996. 660 p.

EQUIPE TÉCNICA DURATEX. Colheita da madeira em florestas com baixo volume por árvore. In: SIMPÓSIO BRASILEIRO SOBRE COLHEITAE TRANSPORTE FLORESTAL, 4., 1999, Campinas. Anais...Viçosa,MG: SIF/UFV, 1999. p.54-72.

DURATEX, Equipe técnica. Colheita da madeira em florestas com baixo volume por árvore. In: SIMPÓSIO BRASILEIRO SOBRE COLHEITAE TRANSPORTE FLORESTAL, 4., 1999, Campinas. Anais...Campinas: SIF, 1999. p.54-72.

FREITAS, L. C. Avaliação de impactos ambientais da inovação tecnológica na colheita florestal. 2008. 118f. Tese (Doutorado em Ciência Florestal) - Universidade Federal de Viçosa, Viçosa, MG, 2008.

FREITAS, L. C. Avaliação quantitativa de impactos ambientais da colheita florestal em plantios eqüiâneos de eucalipto. 2004. 101f. Dissertação (Mestrado em Ciência Florestal) - Universidade Federal de Viçosa, Viçosa, MG, 2004.

FREITAS, L. C. et al. Avaliação quantitativa de impactos ambientais da colheita florestal em dois módulos. Revista Ceres, v.54, n.313, p.292-303, 2007.

FREITAS, L. C.; MACHADO, C. C.; SILVA, G. C. A mecanização da colheita florestal no Brasil. Revista da Madeira, v.20, n.121, p.46-50, 2009.

L. JUNIOR, L.; ZAGONEL, R.; RIBEIRO, F. R. Responsabilidade social no contexto da colheita e transporte florestal: o caso da Aracruz Celulose S.A. In: SIMPÓSIO BRASILEIRO SOBRE COLHEITA E TRANSPORTE FLORESTAL, 8., 2007, Uberlândia. Anais...Viçosa, MG: SIF/UFV, 2007. p.41-52.

LIRA FILHO, J. A. Impactos ambientais da exploração florestal de madeira numa área de floresta plantada em região acidentada, Vale do Rio Doce, MG. 1993. 86f. Dissertação (Mestrado em Ciência Florestal) - Universidade Federal de Viçosa, Viçosa, MG, 1993. 
MACHADO, C. C. Exploração florestal. 6.ed. Viçosa, MG, Universidade Federal de Viçosa, 1989. 34p.

MACHADO, LOPES, E. S. Planejamento. In: MACHADO, C. C. (Ed) Colheita florestal. Viçosa, MG: Universidade Federal de Viçosa, 2008. p.185-230.

MACHADO, C. C., SILVA, E. N., PEREIRA, R. S. O setor florestal brasileiro e a colheita florestal. In: MACHADO, C. C. (Ed) Colheita Florestal. Viçosa, MG: Universidade Federal de Viçosa, 2008. p.5-42.

MALINOVSKI, J. R. et al. Sistemas. In: MACHADO, C. C. (Ed.) Colheita florestal. Viçosa, MG: Universidade Federal de Viçosa, 2008. p.161-184

OREA, D. G. Evaluación de impacto ambiental. Madrid: Editorial Agricola Española, 1998. 260p.

PARISE, D. J. Influência dos requisitos pessoais especiais no desempenho de operadores de máquinas de colheita florestal de alta performance. 2005. 148f. Dissertação (Mestrado em Engenharia Florestal) Universidade Federal do Paraná, Curitiba, 2005.

REZENDE, J. L. P.; PEREIRA, A. R.; OLIVEIRA, A. D. Espaçamento ótimo para a produção de madeira. Revista Árvore, v.7, n.1, p.30-43, 1983.
RODRIGUES, G. S.; CAMPANHOLA, C.; KITAMURA, P. C. Avaliação de Impacto Ambiental da Inovação Tecnológica Agropecuária: AMBITEC-AGRO. Jaguariúna: 2003. 95p. (Embrapa Meio Ambiente Documento, 34).

SEIXAS, F.; OLIVEIRA JUNIOR, E.D.

Compactação do solo devido ao tráfego de máquinas de colheita de madeira. Scientia Forestalis n.60, p. 73-87. 2001.

SILVA, E. Avaliação qualitativa de impactos ambientais do reflorestamento no Brasil. 1994. 309f. Tese (Doutorado em Ciência Florestal) - Universidade Federal de Viçosa, Viçosa, 1994.

SILVA, E. Aspectos políticos e sociais dos impactos ambientais das operações de colheita e transporte florestal. In: SIMPÓSIO BRASILEIRO SOBRE EXPLORAÇÃO E TRANSPORTE FLORESTAL, 2., 1995, Salvador. Anais... Salvador: SIF, 1995. p.14-27.

SILVA, E. Impactos ambientais. In: MACHADO, C. C. (Ed.) Colheita florestal. Viçosa, MG: Universidade Federal de Viçosa, 2008. p.410-435.

SOUZA, A. P.; MINETTI, L. J. Ergonomia aplicada ao trabalho. In: MACHADO, C. C. (Ed.)

Colheita florestal. Viçosa, MG: Universidade Federal de Viçosa, 2002. p.293-310. 
